\title{
0014 GLASSING: THE INVISIBLE DANGER
}

A J M Forsyth* Correspondence: Glasgow Centre for the Study of Violence, Division of Psychology, Glasgow Caledonian University, Glasgow G4 OBA, UK

\subsection{6/ip.2010.029215.14}

In recent decades the use of glass as a medium for manufacturing drinking containers has reduced. Today, milk is commonly sold in cartons, soft drinks in plastic and hot drinks in ceramics. The one category of drink still commonly sold/served in glass vessels is alcohol, paradoxically the only beverage type associated with an increased risk of accidents and serious violence. This presentation will draw together evidence from a variety of studies conducted by the speaker, which, although none were specifically focused on glassing, found this issue to be most salient. These involved licensed premises observation (including the effects of a glassware ban), focus groups with street drinkers, a photo-survey of substance-use litter and a survey/qualitative interviews with convicted violent Young Offenders. Taken together a common theme emerged from these studies; one where alcohol-related glass, especially from off-trade beverages, was associated with injury risk and serious violence, to a greater extent than was the case with more high profile issues such as knife carrying or discarded syringes. This disparity in concern is doubly unfortunate as 'glassing' is a risk/weapon which can more easily be eliminated than knives or other 'sharps'. However owing to the current dominant cultural and economic position occupied by glass in the alcohol market, it is recognised that in the shorter term, the goal should be to initiate gradual change by targeting high risk alcohol environments and alcohol beverages/brands popular with offenders. 